\title{
Postgraduate Course: Smoking Vs. Labor Productivity
}

\section{Hernandez FF* and Gonzalez ES}

Faculty of Medical Science "10 de Octubre”, University of Medical Science of Havana, Cuba

*Corresponding author: Fé Fernández Hernández, Faculty of Medical Science "10 de Octubre", University of Medical Science of Havana, Cuba, Email: fefh@infomed.sld.cu

Research Article

Volume 3 Issue 6

Received Date: November 19, 2020

Published Date: December 02, 2020

DOI: $10.23880 /$ jqhe-16000191

\section{Abstract}

Background: Smoking is close related with no-communicable illness. As consequence from the smoking impact over morbidity and mortality smokers laboring reduces the self labor productivity agree to tobacco consumption. The smoking complexion duties to research and explain it in a multi dimensional form. Also, a postgraduate education is necessary to generalize the knowledge obtained.

Objective: To design a postgraduate course about the relation between smoking and the labor productivity.

Materials and Methods: Theoric methods: inductive - deductive and comparative. Empiric method: bibliographic research.

Results: The postgraduate course "Smoking vs. labor productivity" focus the attention in the relation between smoking and labor productivity. This course was designed especially for health professionals. Nevertheless is recommended the inclusion of professionals from economic sciences to make richer the discussion in class.

Conclusions: It designed a postgraduate course about the relation between smoking and labor productivity. This course saves the condition doing that each subject is supported by the previous.

Keywords: Postgraduate Education; Smoking; Labor Productivity

\section{Introduction}

Smoking is a risk factor close related with nocommunicable illness [1]. In Cuba from 1990 to 2018 the annual incidence from mortality because these mortality causes was 920 cases [2].

As consequence from the smoking impact over morbidity and mortality smokers laboring reduces the self-labor productivity agree to tobacco consumption intensity [3]. These consequences carry to reduce life quality and labor life expectation too [4]. These are the main forms of labor productivity lose attributable to smoking.

The smoking complexion duties to research and explain it in a multi-dimensional form [5]. In the particular case from the smoking social cost because of labor productivity lose attributable to smoking the Health economy role is significant [6].
Also, the postgraduate education is necessary to generalize the knowledge obtained [7]. By this way should be possible the quantification from the smoking in the labor productivity. Also it creates the bases to design labor policies to reduce the smoking impact over the labor productivity too [8].

\section{Objective}

To design a postgraduate course about the relation between smoking and the labor productivity.

\section{Materials and Methods}

\section{Theoric Methods}

Inductive - deductive and comparative. Empiric method: bibliographic research. 


\section{Journal of Quality in Health care \& Economics}

\section{Results}

The postgraduate course "Smoking vs. labor productivity" focus the attention in the relation between smoking and labor productivity. It is formed by six subjects as show the following table 1.

\begin{tabular}{|c|c|c|c|}
\hline Course container & \multicolumn{3}{|c|}{ Hours } \\
\cline { 2 - 4 } & Class & Self-research & Total \\
\hline Health vs. labor productivity & 4 & 12 & 16 \\
\hline Smoking impact over labor health & 4 & 12 & 16 \\
\hline Labor productivity lose because of smoking & 4 & 12 & 16 \\
\hline $\begin{array}{c}\text { Labor productivity lose because tobacco consumption during } \\
\text { working time }\end{array}$ & 4 & 12 & 16 \\
\hline Labor productivity lose because of smoker earlier death & 4 & 12 & 16 \\
\hline Labor policy reducing smoking impact over labor productivity & 4 & 12 & 96 \\
\hline TOTAL & 24 & 72 & 2 \\
\hline
\end{tabular}

Table 1: Course container.

The objective from the first subject is to explain the relation between the labor productivity and the worker health. In this subject the professor must emphasize in the smoking impact over the individual worker health and consequences [9].

The second subject is to explain the incidence from smoking over the labor productivity. In this case the professor must appoint the socioeconomic smoking consequences over the labor health [10].

The third subject must explain the main form from the labor productivity lose attributable to smoking. For that the professor must take account the main ideas from previous subjects [11].

The objective from the fourth subject is to elaborate a theoric and analytic procedure to estimate the social cost from the labor productivity lose because of the tobacco and cigarettes consumption during the working time [12].

The fifth subject include the analytic explication from the over mortality as main cause for the labor productivity lose by earlier death. It focuses on determinate the social cost by earlier death from smokers in labor age. In this subject professor must emphasize that over mortality from smokers is given by the whole life didn't lived front of the no smoker life expectation and not respect the middle life expectation [13].

Finally the sixth subject was included to discuss about possible labor policies to reduce the smoking incidence over the labor productivity. In this way the professor must emphasize the importance from the workplace free of tobacco smoke.
The postgraduate course has the particularity that each subject is supported by the previous. By this form is possible to obtain a logic understanding for a better learning process.

This course was designed especially for health professionals. Nevertheless is recommended the inclusion of professionals from economic sciences to make richer the discussion in class.

\section{Conclusions}

It designed a postgraduate course about the relation between smoking and labor productivity. This course saves the condition doing that each subject is supported by the previous.

\section{References}

1. Alcaraz A, Caporale J, Bardach A, Augustovski F, Pichon Riviere A (2016) Burden of disease attributable to tobacco use in Argentina and the potential impact of the price increase through taxes $40(3)$.

2. Fernández Hernández F, Sánchez González E (2020) The Smoking Economic Burden in the National Institute on Oncology and Radiology from Cuba. Journal of Physical medical \& Rehabitation studies \& Report. 2(2): 1-3.

3. Guerrero López CM, Reynales Shigematsu LM, Jiménez Ruiz JA, Karam Araujo R, Maldonado Cruz CA, et al. (2012Costs for absenteeism attributable to tobacco consumption in the Mexican Institute of Social Security and in Mexico, 2006-2009. Salud Pública de México 54(3): 233-241.

4. Sánchez González E, Fernández Hernández F (2016) The 
loss of labor productivity attributable to smoking. Cuban Journal of Health and Work 17(2): 57-60.

5. Terán Rosero G J, Montenegro Obando BL, Bastidas Guerrón Jeaneth L, Realpe Cabrera IA, Villarreal Salazar FJ, et al. (2017) Critical analysis of social responsibility in health entities. Cuban Journal of Biomedical Research 36(1).

6. Fernández Hernández F, Sánchez González E (2020) Quantitative methods to explain the smoking economic impact. International Journal of Science and Academic Research 1(1).

7. Fernández Hernández F, Sánchez González E (2020) A postgraduate course for the decision taking in the Public Health context. Journal of Medical Care Research and Review 3(8): 413-416.

8. Fernández Hernández F, Sánchez González E, (2020) Diploma course: "Health Economy tools for taking decisions", a useful tool for health managers, Clinical
Reviews and Clinical Trials 2(2).

9. Fernández Hernández F, Sánchez González E (2020) Smoking incidence over the labor health. Journal of Medical Care Research and Review 3(8): 417-419.

10. Sánchez González E, Fernández Hernández F (2017) Tabaquismo y productividad laboral. El ejemplo de Cuba.

11. Sánchez González E, Fernández Hernandez F (2020) Characterization of the Socioeconomic Inequity Attributable to Smoking. Journal of Quality in Health care \& Economics 3(4): 000175.

12. Fernández Hernández F, Sánchez González E (2017) Loss of productivity due to cigarette consumption during the working day. Cuban Journal of Health and Work 18(3): 9-12.

13. Sánchez González E, Fernández Hernández F (2011) Opportunity cost due to premature death of Cuban active smokers in 2011. Cuban Journal of Health and Work 18(2): 26-31. 